\title{
Gestational diabetes mellitus: study of prevalence using criteria of diabetes in pregnancy study group in India and its impact on maternal and fetal outcome in a rural tertiary institute
}

\author{
Neelam Swaroop ${ }^{1}$, Rajani Rawat $^{1 *}$, Pavika Lal $^{2}$, Naresh Pal ${ }^{3}$, Kalpana Kumari ${ }^{1}$, Priya Sharma ${ }^{1}$ \\ ${ }^{1}$ Department of Obstetrics \& Gynaecology, UP Rural Institute of Medical Science and Research, Saifai, Etawah, Uttar \\ Pradesh, India \\ ${ }^{2}$ Department of Obstetrics \& Gynaecology, Rama Medical College, Kanpur \\ ${ }^{3}$ Department of social and preventive medicine, UP Rural Institute of Medical Science and Research, Saifai, Etawah, \\ Uttar Pradesh, India
}

Received: 26 September 2015

Accepted: 31 October 2015

*Correspondence:

Dr. Rajani Rawat,

E-mail: rajanirawat21@gmail.com

Copyright: $\odot$ the author(s), publisher and licensee Medip Academy. This is an open-access article distributed under the terms of the Creative Commons Attribution Non-Commercial License, which permits unrestricted non-commercial use, distribution, and reproduction in any medium, provided the original work is properly cited.

\begin{abstract}
Background: Gestational diabetes mellitus ((GDM) is defined as carbohydrate intolerance of varying degree of severity with onset or first recognition during pregnancy. GDM is associated with adverse fetomaternal outcome. Its early detection and management is essential for better perinatal outcome. The objective of the study was to assess the prevalence of gestational diabetes mellitus among pregnant women of western U.P. using diabetes in pregnancy study group in India (DIPSI) criteria and further assess its impact on fetomaternal outcome.

Methods: This was a prospective study conducted at UP RIMS \& R, Saifai, Uttar Pradesh, India including 225 pregnant women between 24-28 weeks gestational age who attended the antenatal OPD from January 2014 to January 2015.All women were given $75 \mathrm{gm}$ oral glucose irrespective of their meals. Women with blood sugar values $>140 \mathrm{mg} / \mathrm{dl}$ were labeled as GDM and rest as control or non GDM group. All the GDM patients were followed up either with diet or insulin therapy till delivery to study fetomaternal outcome.

Results: Out of 225 Women 22 women $(9.7 \%)$ were diagnosed as having GDM and among risk factors, higher BMI was shown to be significant association $(\mathrm{p}<0.05)$. There was also significant difference among birth weight and neonatal complications in GDM and NON-GDM group $(\mathrm{P}<0.05)$.

Conclusions: Due to high prevalence of GDM in India in our study we concluded that screening is very essential for all pregnant women even in low-risk group. As in our study which was done by single step method of DIPSI which was easy to performed, feasible for remote population. But more studies are needed to further conclude that DIPSI is sufficient for Indian population.
\end{abstract}

Keywords: DIPSI, Fetomaternal outcome, Gestational diabetes mellitus, Oral glucose tolerance test

\section{INTRODUCTION}

Gestational diabetes mellitus defined as carbohydrate intolerance diagnosed for the first time during pregnancy. ${ }^{1}$ The prevalence of GDM ranges from 1- 14\% depending upon the screening method, diagnostic criteria and population screened. High prevalence of GDM around $18 \%$ has been reported in India. ${ }^{2}$ Various screening program with GTT-100 gm glucose or WHO criteria of $75 \mathrm{gm}$ glucose have been observed to diagnose 
and screen DM but need of the hour in Indian setting is the requirement of simple screening test which is less cumbersome to the patients as well as physician. Therefore diabetes in pregnancy study group in India (DIPSI) criteria has gained much importance. The purpose of our study was to know the prevalence of GDM by DIPSI criteria and its effect on fetomaternal outcome.

\section{METHODS}

This was a prospective study which was conducted in department of obstetrics and gynaecology of UP RIMS \& R Safai, Uttar Pradesh, India from January 2014 to January 2015 over a period of one year.

Total numbers of antenatal women with gestational age of 24-28 weeks of pregnancy were enrolled the exclusion criteria were pre-diabetic, severe PET, twin pregnancy. A standardized questionnaire was used and details pertaining to their anthropometrics, family history, medical, and obstetric history and other relevant information were collected. A complete antenatal examination was done. All routine antenatal investigations were sent. After obtaining the informed consent. All women were given 75 gm of oral glucose load with water irrespective of her last meal and venous blood was drawn after 2 hour for estimation of plasma glucose in central laboratory via glucose oxidase peroxidase (GOD-POD) method. If 2 hour plasma glucose value was $>140 \mathrm{mg} / \mathrm{dl}$ it was considered diagnostic of GDM by DIPSI criteria. All screen positive (GDM) women were advised medical nutrition therapy (MNT) for two weeks and those who did not respond to MNT were put on insulin therapy and were followed up to delivery to assess their perinatal outcome.

\section{RESULTS}

A total of 225 healthy pregnant women attending the antenatal OPD were followed up till delivery. The mean age of women was 25.46 years. Out of 225 pregnant women, 22 women $(9.7 \%)$ were diagnosed as GDM using DIPSI recommended 75 gms OGTT. Gestational diabetes mellitus was found to occur more in women above 25 years of age and in multigravidas (Table 1). Majority of GDM women belonged to rural area since our study was carried out in rural institute. When educational status was analysed, most of the women with GDM (40.9\%) were intermediate/high school/middle class and $27.27 \%$ were educated up to primary school. Similarly, majority of women diagnosed to have GDM belonged to upper class showing a positive co-relation.

Table 2 shows that $77.27 \%$ women with GDM had BMI $>25 \mathrm{~kg} / \mathrm{m}^{2}$ showing a significant correlation between GDM and non GDM group (chi-square $=92.5, \mathrm{df}=3$, $\mathrm{p}<0.05)$. Outcomes of women with and without GDM were also studied in terms of mode of delivery, neo-natal complications and birth weight of baby. $54.54 \%$ women with GDM underwent caesarean section as compared to $16.74 \%$ in non GDM group (Table 3). Instrumental delivery rate was higher in GDM women $(18.1 \%)$ as compared to $6.4 \%$ in non GDM group.

Table 1: Socio-demographic profile of the patients.

\begin{tabular}{|c|c|c|c|c|c|}
\hline \multirow[t]{2}{*}{ Parameter } & & \multicolumn{2}{|c|}{$\begin{array}{l}\text { GDM } \\
\mathrm{n}=22\end{array}$} & \multicolumn{2}{|c|}{$\begin{array}{l}\text { Non-GDM } \\
n=203\end{array}$} \\
\hline & & no. & $\%$ & No. & $\%$ \\
\hline \multirow[t]{4}{*}{ Age } & $<20 \mathrm{yrs}$ & 0 & $\mathrm{O}$ & 21 & 10.34 \\
\hline & $20-25 y r s$ & 13 & 59 & 137 & 67.48 \\
\hline & $25-30 y r s$ & 5 & 22.7 & 32 & 15.76 \\
\hline & $>30 \mathrm{yrs}$ & 4 & 18.18 & 13 & 6.4 \\
\hline \multirow[t]{2}{*}{ Gravida } & Primigravida & 6 & 27.27 & 132 & 65.02 \\
\hline & Multigravida & 16 & 72.72 & 71 & 34.97 \\
\hline \multirow[t]{3}{*}{ Residence } & Rural & 13 & 59 & 148 & 72.9 \\
\hline & Semi urban & 1 & 4.54 & 32 & 15.76 \\
\hline & Urban & 8 & 36.36 & 23 & 11.33 \\
\hline \multirow[t]{2}{*}{$\begin{array}{l}\text { Family } \\
\text { history of } \\
\text { diabetes } \\
\text { mellitus }\end{array}$} & Present & 12 & 54.54 & 72 & 35.46 \\
\hline & Absent & 10 & 45.45 & 131 & 64.53 \\
\hline \multirow[t]{3}{*}{$\begin{array}{l}\text { Socio- } \\
\text { economic } \\
\text { status }\end{array}$} & Upper & 17 & & 8 & 3.94 \\
\hline & Middle & 3 & & 82 & 40.39 \\
\hline & Lower & 2 & & 113 & 55.66 \\
\hline
\end{tabular}

Table 2: Distribution of patients according to BMI.

\begin{tabular}{|lllll|}
\hline \multirow{3}{*}{ BMII $(\mathrm{kg} / \mathrm{m} 2)$} & GDM & \multicolumn{3}{c|}{ Non GDM } \\
& $\mathrm{N}=22$ & \multicolumn{3}{c|}{ N=203 } \\
\hline & No. & $\%$ & No. & $\%$ \\
\hline$<18.5$ & 0 & 0 & 38 & 18.71 \\
\hline $18.5-24.9$ & 1 & 4.54 & 110 & 54.18 \\
\hline $25-29.9$ & 17 & 77.27 & 43 & 21.18 \\
\hline$>30$ & 4 & 18.18 & 12 & 5.91 \\
\hline
\end{tabular}

Chi-square $=92.5 ; \mathrm{df}=3 ; \mathrm{p}<0.05$

Table 3: Distribution of cases according to the mode of delivery.

\begin{tabular}{|lllll|}
\hline \multirow{2}{*}{ Mode of delivery } & \multicolumn{3}{c}{ GDM N=22 } & \multicolumn{2}{l|}{ Non GDM } \\
& No. & $\%$ & No. & $\%$ \\
\hline & 6 & 27.27 & 156 & 76.84 \\
\hline Normal delivery & 4 & 18.1 & 13 & 6.4 \\
\hline Instrumental delivery & 12 & 54.54 & 34 & 16.74 \\
\hline Lscs & 6 & 27.27 & 156 & 76.84 \\
\hline Normal delivery & 6
\end{tabular}

Chi-square $=24.3 ; \mathrm{df}=2 ; \mathrm{p}<0.05$

The mean birth weight in women with GDM $(3.3 \mathrm{~kg})$ was higher than in women without GDM $(2.81 \mathrm{~kg})$. The macrosomia rate in GDM group was $45.45 \%$ as 
compared to $7.88 \%$ in non GDM group showing a significant association $(\mathrm{P}<0.05)$.

GDM was found to be significantly associated with neonatal complications especially respiratory distress syndrome and hypoglycaemia.

Table 4: Distribution of cases according to birth weight of baby.

\begin{tabular}{|lllll|}
$\begin{array}{l}\text { Birth weight } \\
(\mathrm{kg})\end{array}$ & $\begin{array}{l}\text { GDM } \\
\mathrm{N}=22\end{array}$ & \multicolumn{3}{c|}{$\mathrm{Non}$ GDM } \\
& No. & $\%$ & No. & $\%$ \\
\hline $2.5-3.0$ & 2 & 9.09 & 64 & 31.52 \\
\hline $3.1-3.5$ & 11 & 50.00 & 106 & 52.21 \\
\hline $3.6-4.0$ & 7 & 31.81 & 20 & 9.85 \\
\hline$>4.0$ & 2 & 9.09 & 13 & 6.40 \\
\hline
\end{tabular}

Chi-square $=11.62 ; \mathrm{df}=3 ; \mathrm{p}<0.05$

Table 5: Distribution of cases according to neonatal complications.

\begin{tabular}{|lllll|}
\hline $\begin{array}{l}\text { Neonatal } \\
\text { complications }\end{array}$ & $\begin{array}{l}\text { ND22 } \\
\text { No. }\end{array}$ & $\%$ & No. & $\%$ \\
\hline & 5 & 22.7 & 154 & 75.8 \\
\hline None & 6 & 27.27 & 11 & 5.4 \\
\hline $\begin{array}{l}\text { Respiratory } \\
\text { distress }\end{array}$ & & & & \\
\hline Hyperbilirubinemia & 1 & 4.5 & 4 & 1.9 \\
\hline Hypoglycaemia & 4 & 18.1 & 0 & 0 \\
\hline $\begin{array}{l}\text { Meconium stained } \\
\text { liquor }\end{array}$ & 1 & 4.5 & 6 & 2.9 \\
\hline $\begin{array}{l}\text { Congenital } \\
\text { anomalies }\end{array}$ & 3 & 13.6 & 5 & 2.4 \\
\hline preterm & 2 & 9.09 & 22 & 10.8 \\
\hline
\end{tabular}

Chi-square $=65.2 ; \mathrm{df}=6 ; \mathrm{p}<0.05$

\section{DISCUSSION}

GDM prevalence has been reported variably from 1.4 to $14 \%$ worldwide and differently among racial and ethnic groups. ${ }^{3}$ Compared to European women, the prevalence of gestational diabetes has increased 11 fold in women from the Indian subcontinent. ${ }^{4}$ The rationale behind the DIPSI criteria is that after a meal normal glucose tolerant female would be able to maintain euglycemia due to a brisk and adequate insulin release. ${ }^{5}$ In case of a pregnant woman who has impaired insulin secretion, there will be a further increase in plasma glucose value after OGTT rather to be euglycemeia.. The prevalence of gestational diabetes mellitus in other studies were - Rajput et al as $7.1 \%$, Wahi et al as $6.94 \%$, Nilofer et al as $6 \%$ and Kalyani KR et al as $8.33 \%$ which was comparable with our study which is $(9.7 \%))^{3,6-8}$

In our study GDM prevalence was more common in upper and middle socioeconomic strata which could be related to multiple factor such as high maternal age, increase pre-pregnancy weight and BMI along with sedentary life style. In our study $77.27 \%$ of women with GDM had BMI more than $30 \mathrm{~kg} / \mathrm{m}^{2}$ which were comparable by the study conducted by Kalyani et al. ${ }^{8}$

Out of 22 GDM women, 14 were treated by dietary modifications while other 8 GDM women were managed by both diet and insulin therapy. Dietary intervention and insulin therapy, with their safety profile, have been considered the gold standard of pharmacotherapy for GDM. On the other hand, a number of trials, including prospective randomized trials, have demonstrated the efficacy of oral hypoglycaemic agents, particularly glyburide and metformin, used in managing pregnant diabetics. $^{9}$

About 54.54\% GDM women had caesarean section as compared to $16.74 \%$ in non GDM group which was significant. In a study conducted by Kalra et al,79\% with GDM had LSCS as compared to $16.74 \%$ in the non GDM group, again justified the fact that there is increase rate of cesarean sections in GDM females. ${ }^{10}$ GDM was also found to be significantly associated with neonatal complications especially respiratory distress syndrome and hypoglycaemia.

\section{CONCLUSIONS}

Our study showed the high prevalence of GDM in our population irrespective of the risk factors present which indicate that every pregnant female in our population should be screened.

DIPSI criteria was also found to be effective and comparable method of screening with respect to GCT/WHO GTT with 75 gm glucose, but larger studies are required to further validate its importance.

Funding: No funding sources

Conflict of interest: None declared

Ethical approval: The study was approved by the Institutional Ethics Committee

\section{REFERENCES}

1. Seshiah V, Balaji V, Balaji MS, Sanjeevi CB, Green A. Gestational Diabetes mellitus in India. J Assoc physician India. 2004;52:707-11.

2. Karcaaltincaba D, Kandemir O, Yalvac S, Guvendag-Guven S, Haberal A. Prevalence of gestational diabetes mellitus and gestational impaired glucose tolerance in pregnant women evaluated by National Diabetes Data Group and Carpenter and Coustan criteria. Int J Gynecol Obstet. 2009;106(3):246-9.

3. Wahi P, Dogra V, Jandial K. Prevalence of gestational diabetes mellitus (GDM) and its outcome in Jammu region. $\mathbf{J}$ Assoc Physicians India. 2011;59:227-30. 
4. Seshiah V, Das K, Balaji V, Joshi SR, Parikh MN, Gupta S.Gestational Diabetes Mellitus-Guidelines. J Assoc Physicians India. 2006;54:622-8.

5. Balaji V,Balaji M,Anjalakshi C, Cynthia A, Arthi T, Seshaiah V. Diagnosis of gestational diabetes mellitus in Asian-Indian women.Indian $\mathbf{J}$ Endocrinaol Metabol. 2011;15:187-90.

6. Rajput R, Yadav Y, Nanada S, Rajput M. Prevalence of gestational diabetes mellitus and associated risk factors at a tertiary care hospital in Haryana.Indian $\mathbf{J}$ Med Red. 2013;137:728-33.

7. Nilofer AR, Raju VS, Dakshayini BR, Zaki SA. Screening in high risk group of gestational diabetes mellitus with its maternal and fetal outcomes. Indian J of Endocrinol Metab. 2012;16:74-8.

8. Kalyani KR. Prevalence of gestational diabetes mellitus, its associated risk factors and pregnancy outcomes at a rural setup in Central India.Int $\mathbf{J}$ Reprod Contracept Gynecol. 2014;3(1):219-24.

9. Paglia MJ, Coustan DR. The use of oral antidiabetic medications in gestational diabetes mellitus.Curr Diab Rep. 2009;9(4):287-90.

10. Kalra P, Kachhwaha CP, Singh HV. Prevalence of gestational diabetes mellitus and its outcome in western Rajasthan. Indian $\mathbf{J}$ Endocr Metab. 2013;17:677-80.

Cite this article as: Swaroop N, Rawat R, Lal P, Pal N, Kumari K, Sharma P. Gestational diabetes mellitus: study of prevalence using criteria of diabetes in pregnancy study group in India and its impact on maternal and fetal outcome in a rural tertiary institute. Int J Reprod Contracept Obstet Gynecol 2015;4:1950-3. 